\title{
From Tradition to Modernity: Economic Growth in a Small World.
}

\author{
Ines Lindner ${ }^{\dagger}$ and Holger Strulik** \\ Leibniz Universität Hannover, Discussion Paper No. 478 \\ ISSN 0949-9962
}

August 2011.

\begin{abstract}
This paper introduces the Small World model (Watts and Strogatz, Nature, 1998) into the theory of economic growth and investigates how increasing economic integration affects firm size and efficiency, norm enforcement, and aggregate economic performance. When economic integration is low and local connectivity is high, informal norms control entrepreneurial behavior and more integration mainly improves search for efficient investment opportunities. At a higher level of economic integration neighborhood enforcement deteriorates and formal institutions are needed to keep entrepreneurs in check. A gradual take-off to perpetual growth is explained by a feedback effect from investment to the formation of long-distance links and the diffusion of knowledge. If formal institutions are weak, however, the economy does not take off but stagnates at an intermediate income level. Structurally, the equilibrium of stagnation differs from balanced growth by the presence of relatively many small firms of low productivity.
\end{abstract}

Keywords: modernization, economic integration, firm size, norms, networks, knowledge spillovers, growth.

JEL: O10; O40; L10; L14; Z13.

\footnotetext{
${ }^{*}$ We I would like to thank Maria Rosaria Carillo, Matteo Cervellati, Karl Dietrich, and participants at seminars in Hannover and Naples and at the conference "Cultural Change and Economic Growth in the Long Run" in Munich for helpful comments.

${ }^{\dagger}$ Free University Amsterdam, De Boelelaan 1105, 1081 HV Amsterdam, The Netherlands, email: ilindner@feweb.vu.nl

${ }^{* *}$ University of Hannover, Wirtschaftswissenschaftliche Fakultät, Königsworther Platz 1, 30167 Hannover, Germany; email: strulik@vwl.uni-hannover.de.
} 


\section{INTRODUCTION}

The transition from a pre-modern or traditional to a modern society is frequently described as modernization. Modernization theory emphasizes the process of increasing social integration and its economic, social, and cultural ramifications. At the economics side, the notion of modernization encompasses the increasing movement of goods, people, and information among formerly disjunct subpopulations, which is typically accompanied by increasing efficiency, increasing firm size, and economic growth (Rostow, 1959, Kuznets, 1966).

At the social and cultural side, modernization is characterized by a change of values and believes (Inglehart and Baker, 2000). The individual becomes more important and the family and local community decreases in importance. Strong local ties are augmented or replaced by weak long-distance links (Granovetter, 1973). Cultural change may have important repercussions on economic performance, in particular, if the vanishing power of localized norms is not appropriately replaced by formal institutions. Modernization may entail vanishing trust and trustworthiness and lead to non-cooperative behavior and increasing inefficiency of the economy (Polanyi, 1957, Fukuyama, 1995).

The present paper offers a network-based theory of economic growth that integrates economic as well as social aspects of modernization. It treats cultural change as cause and consequence of economic development and investigates the process of modernization from a traditional society towards an economically fully integrated modern society. A traditional society is conceptualized as a largely localized network, in which people are predominantly interacting with their neighbors. High local connectivity prevents the search for high-yield investment opportunities and implies the existence of inefficiently many small firms. An advantage of high local connectivity, however, is a high degree of neighborhood monitoring which prevents entrepreneurs from misbehaving and guarantees investors a fair return on their investment.

A modern society, in contrast, is conceptualized as a global network with little local clustering. Given the high presence of long-distance links it is relatively easy to search for high-investment opportunities. This effect of economic integration leads - taken for itself - to a higher concentration of capital at firms of high productivity, increasing average firm size, and the gradual extinction of small low-productivity firms. The loss of local connectivity, however, entails also a loss of neighborhood control. Formal (state-wide) institutions are needed to ensure honest (cooperative) behavior. Without such institutions in place, entrepreneurs have an incentive to 
enrich themselves at the expense of their "anonymous" investors. Anticipating this behavior, people are reluctant to invest and a suboptimally high number of small, inefficient firms persists.

The economic consequences of social relationships and their basis on shared values and norms is frequently discussed under the heading of "social capital". Researchers of social capital thereby emphasize the crucial role of networks for a proper understanding of the phenomenon: "The study of social capital is that of network-based processes that generate beneficial outcomes through norms and trust" (Durlauf and Fafchamps, 2005). Over the last decade, the role of social capital for economic growth has been documented empirically (e.g. Knack and Keefer, 1997, Zak and Knack, 2001, Ahlerup et al., 2009, Tabellini, 2010) and certain aspects of social capital have been investigated theoretically (e.g. Zak and Knack, 2001, Annen, 2003, Routledge and van Amsberg, 2003, Francois and Zabojnik, 2005, Guiso et al., 2008, Tabellini, 2008, Kumar and Matsusaka, 2009). So far, however, an evolving network representing the pros and cons of strong and weak ties has not yet been integrated into the standard theory of economic growth.

The present paper offers a network-based theory of economic development by integrating the Small World model (Watts and Strogatz, 1998) into a standard model of economic growth. The Small World model is particularly suited for the analysis of economic integration because it relates important characteristics of networks - the ease of information exchange and the structure of local communities - to geographical proximity by means of characteristic coefficients which can be calculated analytically or approximated through mean field theory. This way, economic exchange through the net can be conveniently analyzed without any concrete specification of the network itself but by focussing on network properties summarized in simple coefficients, a fact that yields a great reduction of complexity.

Specifically, we consider a society of overlapping generations which is heterogenous with respect to entrepreneurial talent. In a completely localized world the number of firms coincides with the number of families (subsistence farming). With increasing economic integration - modeled as the formation of long-distance links in the Small World model- people start investing in high-productivity firms and subsequently average firm size and income per capita increases and the number of low-productivity firms falls. Entrepreneurs have an information advantage which they may exploit at the expense of investors. At a low level of economic integration, with a lot of local connectivity, neighborhood enforcement limits the appropriation possibilities of entrepreneurs. At a higher level of economic integration, however, the clustering coefficient and 
therewith neighborhood enforcement deteriorates. Formal institutions (rule of law) are needed to keep entrepreneurs in check.

By introducing a feedback from investment and capital accumulation to the formation of long-distance links and the diffusion of knowledge, it is shown that the theory explains a gradual take-off to perpetual economic growth along which long-distance (anonymous) business relations become dominating and average firm size in the economy decreases. Perpetual growth, however, requires investor protection by the law. Without enforceable formal institutions an economy relying on community enforcement gets stuck in the midst of the process of economic integration. The social disadvantage of integration from loss of local connectivity and local norm enforcement counterbalances the social advantage from knowledge diffusion and efficient investment opportunities. The economy stagnates at a low level of trustworthiness and trust and at an industrial structure characterized by inefficiently many small firms of low productivity.

The new theory shares perhaps most with the papers by Zak and Knack (2001) and Farmer and Kali (2007). Zak and Knack consider heterogenous interacting investors and investment brokers. Brokers have an information advantage and the incentive to enrich themselves at the expense of investors. They are kept in check by formal and informal institutions. With increasing social distance between broker and investor the power of informal institutions decreases and the incentive to cheat increases. The paper shares with the present one the emphasis on (social) distance as a determinant of trust, investment and efficiency. Business relations, however, are not modeled as a dynamic, evolving network and the theory is not embedded into an endogenous growth framework. ${ }^{1}$

The network-modeling of the present paper was to some extent inspired by Farmer and Kali (2007) who integrated the Small World model into a game-theoretic framework and investigated the consequences of (exogenous) network evolution on economic behavior. The present paper develops the original ideas further by integrating the Small World approach into a dynamic general equilibrium context and by establishing a feedback mechanism from investment behavior to the formation of long-distance links.

\footnotetext{
${ }^{1}$ Recently, Karlan et al. (2009) investigated trust and investment (loans) in an explicit network which shares many characteristics with the Small World model. They do not address, however, general equilibrium issues and economic growth. Fogli and Feldkamp (2011) investigate innovation activities in two given (i.e. non-evolving) networks. Like us they are concerned with the impact of network structure on the flow of knowledge. But they do not consider how (evolving) network structure affects social norms, occupational choice, and investment activities.
} 
The paper is also related to the literature on firm size and development (e.g. Lucas, 1978, Kremer, 1993, Gollin, 2007). It offers a novel, complementing explanation for the negative correlation between the degree of economic development (GDP) and average firm size. As in the earlier literature, firm size is found to be negatively associated with TFP. But whereas the earlier literature assumes time-invariant TFP, the present paper treats TFP as endogenous and evolving over time. It suggests a less benign view on the relatively large number of small firms observable in many less developed countries. Small firm size is interpreted as an expression of inferior formal institutions. For societies relying to a large degree on informal (local) norm enforcement, at some stage further economic integration is predicted to lead predominantly to an erosion of local connectivity and trust and trustworthiness. Consequently these societies stagnate at an intermediate level of economic integration at which entrepreneurs can be kept in check by local norm enforcement, which implies the incidence of inefficiently many firms of small size and low productivity.

Figure 1: Proportion of Workforce of Entrepreneurs and Own-Account Workers Across Countries
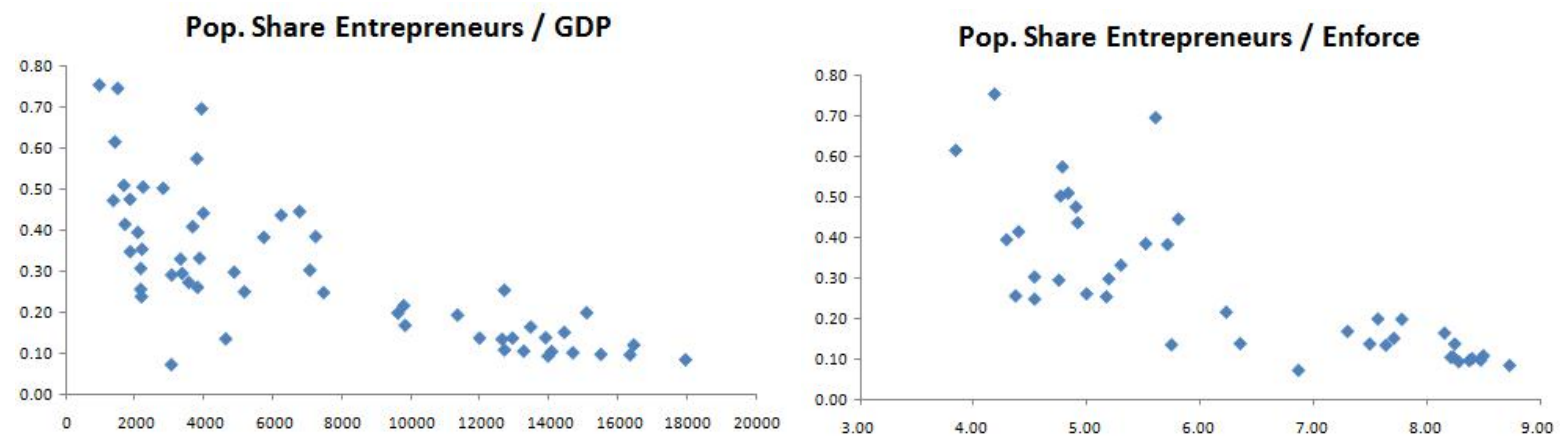

Left: Proportion of entrepreneurs against GDP per capita 1985, Data from Gollin (2008). Right: Proportion of entrepreneurs against enforceability of contracts, Data from Gollin (2008) and Djankov et a. (2003).

The novel view on firm size can be illustrated with help of Figure 1. The available theory argues that it is efficient to have many small firms when TFP (and thus GDP) is low (Gollin, 2008, left hand side of Figure 1). The present theory argues that weak formal institutions (low index of contract enforceability) leads to the presence of inefficiently many small firms, which in turn leads to low aggregate TFP and GDP (right hand side of Figure 1). ${ }^{2}$

\footnotetext{
${ }^{2}$ See La Porta et al. (1997) for evidence on the correlation of firm size, trust, and family ties. See Humphrey and Schmitz (1998) and Fafchamps (2001) for surveys on firm behavior and business networks in developing countries and in Sub Saharan Africa.
} 
The remainder of the paper is organized as follows. The next section introduces the small world model, Section 3 sets up the economic model, and Section 4 discusses dynamics and comparative steady-states for a given network. Section 5 introduces the feedback effect from capital accumulation to network formation. It derives the main results of the theory of modernization and comparative economic development. Section 6 introduces a second feedback effect from network formation to knowledge spillovers and endogenous growth and illustrates how the theory of modernization explains the gradual take-off to perpetual economic growth as well as stagnation at an intermediate level of economic integration. Section 7 concludes.

\section{The Small World Model}

The Small World model was originally developed by Watts and Strogatz (1998) and has since then been empirically verified for a plethora of biological and social phenomena (see Newmann, 2003 , for an overview). It is particularly suited for the analysis of economic integration because it relates important characteristics of networks - the ease of information exchange and the structure of local communities - to geographical proximity by means of simple characteristic coefficients which can be analytically calculated or approximated through mean field theory. This way, economic exchange through the net can be conveniently analyzed without any concrete specification of the network itself but by focussing on network properties summarized in simple coefficients, a fact that yields a great reduction of complexity.

Consider a social network where vertices (nodes) are persons and edges (links) indicate whether any two persons know each other. Two important coefficients that characterize such a network are the average path length $L$ and the clustering coefficient $C$. The average path length is an indicator of social distance. It gives the average shortest path between any two persons in the net. Ever since Milgram's (1967) famous “Six Degrees of Separation' experiment it is known that this distance is short in modern societies. More specifically, one speaks of the "small world" property when the average path length grows logarithmically with the size of the network (the number of persons). For our economic model the average path length is an appropriate and convenient indicator for the ease at which information about profitable investment opportunities can be gathered through the net. ${ }^{3}$

\footnotetext{
${ }^{3}$ The literature distinguishes between the small world model and the small world property. A small world model investigates network characteristics when links between edges of an initially regular network on a lattice are randomly rewired. The small world property (or -effect) describes the phenomenon that a few long-distance links are already sufficient to establish a short average path length between edges in a network. In the small world
} 
The clustering coefficient $C$ is an indicator for the connectivity of local communities. It gives the average probability that two persons that are connected to any person are also directly connected with each other, that is the probability that someone's friends (trading partners) are also friends (trading partners) with each other. The clustering coefficient is thus a local property whereas the average path length is a global property. In Granovetter's (1973) famous terminology one could say that $C$ is an indicator of the relative importance of strong ties. A high degree of social embeddedness (high $C$ ) implies that there is a lot of community monitoring and control over one's activities. We use this fact for our purpose by assuming that entrepreneurs have an information advantage vis a vis investors about the return on capital and that the degree to which they can exploit this advantage to enrich themselves at the expense of investors is decreasing in the clustering coefficient.

The small world model interpolates smoothly between a "large world", i.e. a regular network in which average path length as well as the clustering coefficient assume their maximum values, and a random network, in which path length as well as clustering are minimal. The original model of Watts and Strogatz (1998) generates this feature by rewiring edges with other edges that are randomly chosen from the net. The process of globalization is approximated by continuously increasing from zero to unity the fraction $p$ of edges that are allowed to be rewired.

Figure 2: Small World Model
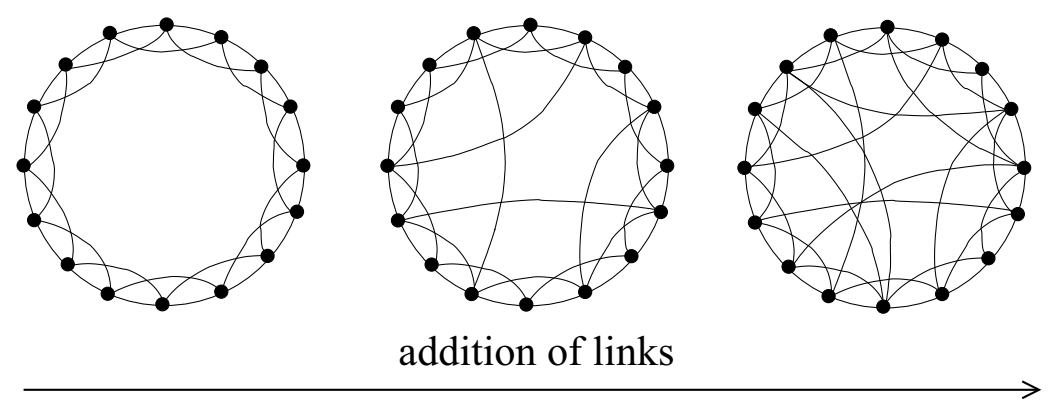

Left: one-dimensional lattice with connections between all vertex pairs by $m=2$ or fewer lattice spaces away. A Small World is created by randomly adding shortcuts to the edges.

Here we consider a slight modification introduced by Newman et al. (2000) and illustrated in Figure 2. The variable $p$ now gives the probability per edge that there exists a shortcut to model the small wold property is observed at low $p$ when $L(p)$ is already low but $C(p)$ is still high, that is, for example, in the central network of Figure 2; see Newman (2003). 
another randomly chosen edge on the lattice keeping the original neighborhood intact. Thus, with increasing $p$ the original Watts-Strogatz model creates long-distance (or global) links by destroying local ones whereas the modification of Newman et al. creates global links while preserving local ones. Figuratively speaking, increasing economic integration, conceptualized as increasing $p$, is introduced in the original model by continuously destroying local neighborhoods and in the modified version by making local neighborhoods increasingly unimportant. Besides more realism the modified version entails the advantage that crucial network characteristics can be expressed analytically.

The idea of the small world model can best be illustrated by considering a network on a one-dimensional lattice as in Figure 2. To begin with, any vertex (person) is connected with his direct neighbors that are $m$ or fewer lattice spaces away. In the example of Figure $2, m=2$. Each person is connected to 4 neighbors, 2 at each side. Coming from low $p$ adding more longdistance links has mainly the effect of reducing the shortest distance between edges such that a low average distance $L(p)$ goes along with a yet high clustering coefficient $C(p)$. When $p$ is high and $L(p)$ is already low, in contrast, further adding long-distance links has mainly the effect of reducing the importance of local neighborhoods, i.e. of reducing the clustering coefficient.

Figure 3: Average Path Length and Clustering Coefficient

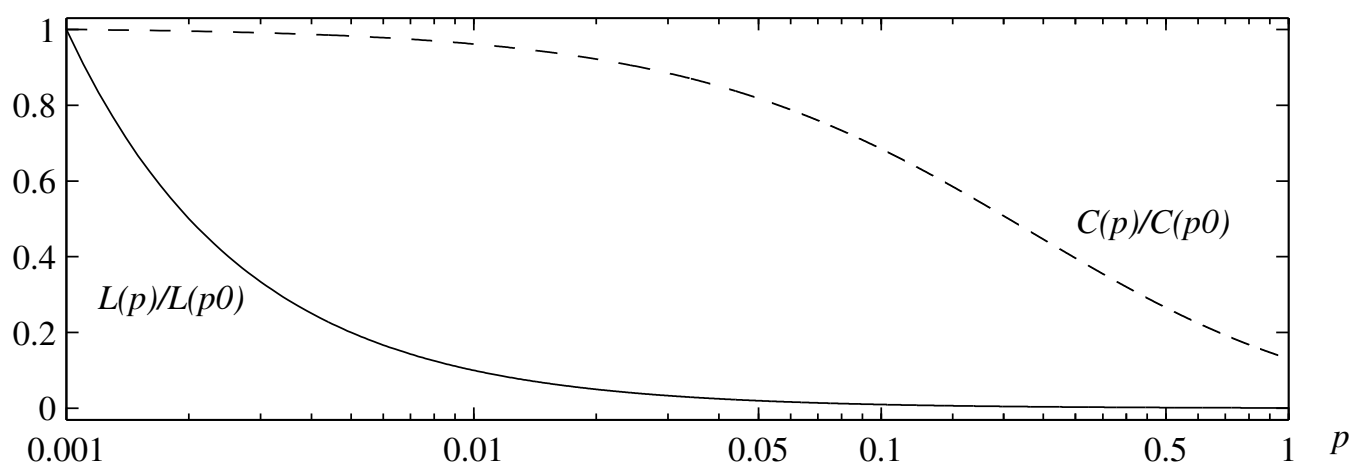

The Small World model's network characteristics for alternative probabilities of shortcuts $p$. $C(p) / C\left(p_{0}\right)$ : normalized clustering coefficient, $L(p) / L\left(p_{0}\right)$ normalized average path length. $p$ runs from 0.001 to 1 . Example for $m=5, N=100000$.

For any given $p$ the clustering coefficient can be computed analytically as $C(p)=3 / 2(m-$ 1) $/[(2 m-1)+4 m p(p+2)]$. Average path length, for which no explicit solution exists, can be approximated. Let $N$ denote the number of persons in the network. The total number of shortcuts is then given by $z=p m N$ and an approximation of $L(p)$ is $L(p)=(N / 2 m)\left(z^{2}+\right.$ 
$2 z)^{-1 / 2} \tanh ^{-1}(z /(z+2))^{1 / 2}$, see Newman (2003). Figure 3 shows network behavior for $m=5$ and $N=100000$. As common in the literature we have normalized $C(p)$ and $L(p)$ by dividing by initial $C(0)$ and and initial $L(0)$. respectively. Note that the $p$ axis is scaled logarithmically. The example thus demonstrates the crucial feature of the small world model: At small $p$, average path length drops drastically while $C(p)$ falls only very gradually. In other words, for rising $p$, shorter average distance is the main observable outcome at low degrees of economic integration (low $p$ ) while lower clustering (lower social connectivity) is the main observable outcome at later stages of economic integration. The interplay of $L(p)$ and $C(p)$ will be the main driver in our model of modernization and economic growth. Formally, these qualitative features of the Small world model are summarized as follows.

Assumption 1 (Small World). $L^{\prime}(p)<0, L^{\prime \prime}(p)>0$ and $C^{\prime}(p)<0, C^{\prime \prime}(p)<0$. There exist a $\bar{p} \in[0,1]$ such that $\left|C^{\prime}\right|<\left|L^{\prime}\right|$ for $p<\bar{p}$ and vice versa for $p>\bar{p}$. There exist a $\tilde{p} \in[0,1]$ such that $\left|C^{\prime \prime}\right|<\left|L^{\prime \prime}\right|$ for $p<\tilde{p}$ and vice versa for $p>\tilde{p}$.

\section{The Basic Model}

3.1. Setup of Society. Consider an economy populated by two overlapping generations. Members of the young generation supply one unit of labor, earn wages $w_{t}$, and decide how to divide labor income between expenditure for current consumption $c_{t}^{1}$ and savings for the second period of life. Members of the old generation do not supply any labor for wage work. They follow a career as either investors or entrepreneurs. Entrepreneurs are operating firms and employ labor supplied by the young generation and capital provided by investors (and of course by entrepreneurs themselves). At the end of the second period of life investors and entrepreneurs receive the return on their investment and spend it on consumption $c_{t+1}^{2}$.

Suppose that the young individuals of period $t$ maximize expected utility from life-time consumption $u_{t}=\log \left(c_{t}^{1}\right)+\beta \log \left(c_{t+1}^{2}\right)$ where $\beta$ is the discount factor. They face the current period's

budget constraint $c_{t}^{1}=w_{t}-s_{t}$ and the next period's budget constraint $c_{t+1}^{2}=R_{t+1} s_{t}$ where $R_{t+1}$ is the expected gross interest rate and $s_{t}$ are savings. This standard OLG setup provides the well-known solution for savings (1).

$$
s_{t}=\frac{\beta}{1+\beta} \cdot w_{t}
$$


The occupational choice and the institutional environment make the rate of return on investment career- and situation-specific. To begin with, not everybody is equally talented as entrepreneur and not all firms at the market are equally productive. Moreover, entrepreneurs have an information advantage vis a vis investors and may use this fact in order to enrich themselves at the expense of low returns to investors, in particular if there is little monitoring by local communities and if formal institutions are weak and contracts are hard to enforce.

In order to integrate these ideas conveniently into the model we assume that a given (small) fraction $n^{H}$ of the population is of high-ability as entrepreneur and runs a business with total factor productivity $A^{H}$. The remainder of the population has comparatively low entrepreneurial skills. A variable and yet to be determined fraction $n_{t}^{L}$ nevertheless runs a business with total factor productivity $A^{L}<A^{H}$. The others become investor. Naturally, investors prefer to invest in high-productivity firms. For that purpose they search (through the economic network) for high-ability entrepreneurs. Let us suppose that they find one with probability $\mu_{t}$. Since there are $1-n^{H}-n_{t}^{L}$ investors, a share of $\mu_{t}\left(1-n^{H}-n_{t}^{L}\right)+n^{H}$ of the population manages to allocate their funds to high-productivity firms while the remainder invests into low-productivity firms. The ratio of aggregate capital in the low-productivity segment vs. the high-productivity segment of the economy is thus given by $x_{t}$ in $(2)$.

$$
x_{t} \equiv \frac{n_{t}^{L} k_{t}^{L}}{n^{H} k_{t}^{H}}=\frac{\left(1-\mu_{t}\right)\left(1-n^{H}-n_{t}^{L}\right)+n_{t}^{L}}{\mu_{t}\left(1-n^{H}-n_{t}^{L}\right)+n^{H}}
$$

where $k_{t}^{H}$ and $k_{t}^{L}$ are the capital stocks of a high- and low-productivity firm.

Let $R_{t}^{H}$ and $R_{t}^{L}$ denote the gross rate of return of a unit of capital. We model the fact that entrepreneurs are able to appropriate a higher rate of return at the expense of investors by assuming that investors get the gross return $R_{t}^{H, I}=\lambda_{t} R_{t}^{H}$ and $R_{t}^{L, I}=\lambda_{t} R_{t}^{L}, 0<\lambda_{t} \leq 1$. All investors in the high-productivity segment thus earn $\mu_{t}\left(1-n^{H}-n_{t}^{L}\right) \lambda_{t} R_{t}^{H}$ per unit of investment implying that all high-ability entrepreneurs appropriate profits $\left[\mu_{t}\left(1-\lambda_{t}\right)\left(1-n^{H}-n_{t}^{L}\right)+n^{H}\right] R_{t}^{H}$ per unit of investment. From this, and analogous reasoning for low-ability firms, we obtain the rate of return applicable to high- and low-ability entrepreneurs as shown in (3).

$$
\begin{aligned}
R_{t}^{H, E} & =\frac{\mu_{t}\left(1-\lambda_{t}\right)\left(1-n^{H}-n_{t}^{L}\right)+n^{H}}{n^{H}} \cdot R_{t}^{H}, \\
R_{t}^{L, E} & =\frac{\left(1-\mu_{t}\right)\left(1-\lambda_{t}\right)\left(1-n^{H}-n_{t}^{L}\right)+n_{t}^{L}}{n_{t}^{L}} \cdot R_{t}^{L} .
\end{aligned}
$$


The variable $\lambda_{t}$ measures the safety of investments. It is an indicator of investment protection (La Porta et al., 2008). For $\lambda_{t}=1$ we say that investors get a fair return. The (correctly) expected $\lambda_{t}$ serves also as a measure of trust and trustworthiness. The variable $\mu_{t}$ measures the efficiency of search for investment opportunities. In Section 4 and $5 \lambda_{t}$ and $\mu_{t}$ will be explained by static and evolving network structure, respectively.

While it is always rational for high-ability types to become an entrepreneur, there exists a trade-off for low-ability types. If many follow a career as entrepreneur, investment per firm is small implying that the total return that can be appropriated at the expense of investors is also small. This can be verified by taking the derivative in (3) with respect to $n_{t}^{L}$. Alternatively the low-ability types may consider to become an investor. Such a career is particularly attractive if the probability to find a high-ability entrepreneur is high. More specifically, given free entry into entrepreneurship, an equilibrium condition requires that low-ability types are indifferent between becoming entrepreneur or investor. For that to be the case expected returns have to be the same in both occupations, as stated in (4).

$$
\mu_{t} R_{t}^{H, I}+\left(1-\mu_{t}\right) R_{t}^{L, I}=R_{t}^{L, E}
$$

The modeling of investment allocation and occupational choice is certainly crude with respect to fully modernized economies in which investment is channeled to firms through the stock market. The model captures this fact in an abstract way by $\mu \rightarrow 1$, that is by assuming that high-productivity firms can be found with certainty. For less developed countries, however, the present modeling of capital markets captures some elements of reality that are lost in abstraction in standard models of economic growth. For Sub-Saharan Africa, for example, Fafchamps (1994, pp. 8-9) concludes:

"Sub-Saharan Africa is generally characterized by the absence of a stock market altogether. Given that the modern sector is small and largely public owned, this is hardly surprising. But it means that small investors who wish to invest part of their savings in high-return/high-risk investments are not able to do so via any organized market. This has the interesting consequence that the only possible form of high-return/high-risk investment is either creating one's own enterprise, or financing the enterprise of close friends and relatives whose skills and performance can be monitored. In other words, the absence of a capital market redirects part of 
savings toward small enterprises. The available evidence indeed indicates the absolute predominance of own savings and, to a lesser extent, funds from friends and relatives as sources of ME [microenterprises] capital. The contribution of formal credit and moneylenders is extremely small."

3.2. Firms and Markets. Output (GDP) is produced competitively by high- and low-productivity firms. High-ability entrepreneurs manage to produce more output from any given vector of inputs, that is their firms display higher total factor productivity. Specifically, suppose firm $j \in\{L, H\}$ produces with Cobb-Douglas technology $y_{t}^{j}=A^{j}\left(k_{t}^{j}\right)^{\alpha}\left(h_{t}^{j}\right)^{1-\alpha}$, where $k_{t}^{j}$ and $h_{t}^{j}$ are capital and labor input. Homogenous labor earns a wage $w_{t}$ according to its marginal product.

$$
w_{t}=(1-\alpha) A^{H}\left(k_{t}^{H} / h_{t}^{H}\right)^{\alpha}=(1-\alpha) A^{L}\left(k_{t}^{L} / h_{t}^{L}\right)^{\alpha} .
$$

Depending on whether submitted to a high- or low-productivity firm, each unit of capital earns the gross rate of return $R_{t}^{H}$ or $R_{t}^{L}$.

$$
R_{t}^{H}=\alpha A^{H}\left(k_{t}^{H} / h_{t}^{H}\right)^{\alpha-1}, \quad R_{t}^{L}=\alpha A^{L}\left(k_{t}^{L} / h_{t}^{L}\right)^{\alpha-1} .
$$

Inserting (5) into (6) we get the ratio of returns on investment in high- and low-productivity firms as determined by the differential between high and low entrepreneurial skills (7).

$$
R_{t}^{H} / R_{t}^{L}=\left(A^{H} / A^{L}\right)^{1 / \alpha} \equiv a .
$$

Note that $a>1$. High-ability entrepreneurs achieve a higher rate of return on capital.

Finally, labor market clearing requires $n_{t}^{L} h_{t}^{L}+n^{H} h_{t}^{H}=1$. Inserting (5) and then substituting (2) we obtain firm size of a high-productivity firm (measured by employment).

$$
h_{t}^{H}=\frac{1}{n^{H}\left(1+\frac{x_{t}}{a}\right)} .
$$

Note that $x_{t}$ is a unique function of the share of low-ability entrepreneurs in the population, $n_{t}^{L}$. Thus, once $n_{t}^{L}$ has been determined, we get equilibrium firm size from (8) and can then solve successively for all other macroeconomic aggregates.

3.3. Equilibrium Number and Size of Firms. Subdividing (4) by $R_{t}^{L, I}$ and inserting (3) and (7), the equilibrium condition for career choice becomes $\mu_{t} a+\left(1-\mu_{t}\right)=\left[\left(1-\mu_{t}\right)\left(1-\lambda_{t}\right)(1-\right.$ 
$\left.\left.n^{H}-n_{t}^{L}\right)+n_{t}^{L}\right] /\left(\lambda_{t} n_{t}^{L}\right)$, which can be solved for the equilibrium share of low-productivity firms.

$$
n_{t}^{L}=\frac{\left(1-\lambda_{t}\right)\left(1-\mu_{t}\right)\left(1-n^{H}\right)}{\left(a \lambda_{t}-1\right) \mu_{t}} .
$$

Naturally, we see from (9) that if entrepreneurs cannot appropriate any returns from investors (i.e. if $\lambda_{t}=1$ ) or if high-ability entrepreneurs can be found with certainty (i.e. if $\mu_{t}=1$ ), there is no incentive for low-ability types to become entrepreneur and there are no low-productivity firms present in the market.

A feasible solution requires that $n_{t}^{L} \geq 0$ and $n_{t}^{L}+n^{H} \leq 1$. In order to avoid the distracting discussion of corner solutions we impose a (mild) condition which guarantees that (9) provides a feasible interior solution. It requires that $\lambda$ and $\mu$ lie between certain boundaries..

Assumption 2 (Feasibility). $1 /\left[a<\lambda_{\min } \leq \lambda_{t} \leq \lambda_{\max } \leq 1\right.$ and $\left(1-\lambda_{\max }\right) /\left[\lambda_{\max }(a-1)\right] \leq$ $\mu_{\min }<\mu_{t} \leq \mu_{\max }<1$.

Later on, $\lambda_{\min }$ serves as a proxy for the quality of formal institutions. For $\lambda_{\min }=\lambda_{\max }$ (invariable $\lambda$ ) we observe the special case in which the safety of investments does not depend on informal institutions (neighborhood enforcement).

Taking derivatives of (9) we obtain

$$
\begin{array}{ll}
\frac{\partial n_{t}^{L}}{\partial \lambda_{t}}=-\frac{(a-1)\left(1-\mu_{t}\right)\left(1-n^{H}\right)}{\left(a \lambda_{t}-1\right)^{2} \mu_{t}}<0, & \frac{\partial n_{t}^{L}}{\partial \mu_{t}}=-\frac{\left(1-\lambda_{t}\right)\left(1-n^{H}\right)}{\left(a \lambda_{t}-1\right) \mu_{t}^{2}}<0, \\
\frac{\partial n_{t}^{L}}{\partial a}=-\frac{\lambda_{t}\left(1-\lambda_{t}\right)\left(1-\mu_{t}\right)\left(1-n^{H}\right)}{\left(a \lambda_{t}-1\right)^{2} \mu_{t}}<0, & \frac{\partial n_{t}^{L}}{\partial n^{H}}=-\frac{\left(1-\lambda_{t}\right)\left(1-\mu_{t}\right)}{\left(a \lambda_{t}-1\right) \mu_{t}}<0 .
\end{array}
$$

The following proposition summarizes the results.

Proposition 1. The number of low-productivity firms in equilibrium is decreasing in the safety of returns to investors $\left(\lambda_{t}\right)$, the probability to find high-ability entrepreneurs for one's investment $\left(\mu_{t}\right)$, the relative productivity advantage of high-productivity firms (a), and the number of high-ability entrepreneurs.

Intuitively, the incentive for a low-ability type to become entrepreneur is low if investors get a relatively large share of the return on capital ( $\lambda_{t}$ is high), if it is relatively easy to find high-yield investment opportunities ( $\mu_{t}$ is high), and if the spread between low-ability and highability returns $(a)$ is large. Naturally, there exist fewer low-ability firms when there are more high-ability entrepreneurs $\left(n^{H}\right)$. 
Inserting (9) in (2) and taking the derivatives we obtain

$$
\begin{aligned}
& \frac{\partial x_{t}}{\partial \lambda_{t}}=-(a-1)\left(1-\mu_{t}\right)\left(1-n^{H}\right) D<0, \quad \frac{\partial x_{t}}{\partial \mu_{t}} \quad=-(a-1)\left(a \lambda_{t}-1\right)\left(1-n^{H}\right) \lambda_{t} D<0, \\
& \frac{\partial x_{t}}{\partial a}=-\left(1-\lambda_{t}\right)\left(1-\mu_{t}\right)\left(1-n^{H}\right) \lambda_{t} D<0, \quad \frac{\partial x_{t}}{\partial n^{H}}=-(a-1)\left(a \lambda_{t}-1\right)\left(1-\mu_{t}\right) \lambda_{t} D<0,
\end{aligned}
$$

with $D \equiv 1 /\left\{1-\lambda_{t}\left[1-\left(1-n^{H}\right)(1-a) \mu_{t}-(1-a) n^{H}\right]\right\}^{2}$. Recall from (8) the negative association between the share of capital allocated to low-productivity firms $x_{t}$ and the size of high-productivity firms $h_{t}^{H}$. The following proposition summarizes the result.

Proposition 2. The share of aggregate capital allocated to low-productivity firms in equilibrium $x_{t}$ is decreasing in the safety of returns to investors $\left(\lambda_{t}\right)$, the probability to find highability entrepreneurs for one's investment $\left(\mu_{t}\right)$, the relative productivity advantage of highproductivity firms (a), and the number of high-ability entrepreneurs. Consequently the size of high-productivity firms is increasing in $\lambda_{t}, \mu_{t}$, and a.

Intuitively, a higher incentive for low-ability types to become investor rather than entrepreneur at the micro-level manifests itself at the macro-level by a lower share of aggregate capital allocated to low-productivity firms, which in turn implies that high-productivity firms are bigger.

\section{Dynamics and Long-Run Equilibrium for Given Network}

In this section we investigate the economy for a given network, i.e. for given $\lambda_{t}=\lambda$ and $\mu_{t}=\mu$ for all $t$. This allows us to identify the unilateral impact of economic integration (modernization) on economic performance with means of comparative static analysis. In the next section we discuss feedback effects, i.e. the interaction of economic development and modernization. For given $\lambda$ and $\mu$ dynamics of the economy are isomorph to the standard overlapping generations model and can be represented in one equation. Next period's capital in the high-productivity sector is equal to this period's aggregate wage income spent on investment in high-productivity firms:

$$
n^{H} k_{t+1}^{H}=\left[\mu\left(1-n^{H}-n^{L}\right)+n^{H}\right] \frac{\beta}{1+\beta} w_{t}=\left[\mu\left(1-n^{H}-n^{L}\right)+n^{H}\right] A\left(k_{t}^{H}\right)^{\alpha}\left(h_{t}^{H}\right)^{-\alpha} .
$$

The right hand side of the equation is obtained by inserting wages from (5) and subsuming all constants in the term $A \equiv \beta(1-\alpha) A^{H} /(1+\beta)$. 
Inserting employment from (8) and noting that $x_{t}=x$ for an invariant network, we get a first-order difference equation for the evolution of capital per high-productivity firm.

$$
k_{t+1}^{H}=\left[\mu\left(1-n^{H}-n^{L}\right)+n^{H}\right] A\left(1+\frac{x}{a}\right)^{\alpha}\left(n^{H}\right)^{\alpha-1} \cdot\left(k_{t}^{H}\right)^{\alpha} .
$$

Inspect (11) to see that for $\lambda \rightarrow 1$ and thus $n^{L} \rightarrow 0$ and $x \rightarrow 0$ the model boils down to the standard OLG model, i.e. $n^{H} k_{t+1}^{H}=A\left(n^{H} k_{t}^{H}\right)^{\alpha}$. For general $\lambda$ equation (11) differs only by a constant from the standard model. Diagrammatically, the unique, globally stable steady-state is found where the concave curve given by the right hand side of (11) intersects the identity line.

Proposition 3. For given network structure $\lambda$ and $\mu$, the economy converges towards a globally stable steady-state.

In order to inspect the comparative statics it is useful to re-write (10) evaluated at the steadystate $\left(k^{H}=k^{H *}, h^{H}=h^{H *}\right)$ in terms of the capital-intensity in the high-productivity sector: $\kappa^{*} \equiv\left(k^{H^{*}} / h^{H^{*}}\right)^{1-\alpha}=\left[\mu\left(1-n^{H}-n^{L}\right)+n^{H}\right] A(1+x / a)$. After inserting $x$ from (2) this expression simplifies to (12).

$$
\kappa^{*}=\frac{A}{a}\left\{1+(a-1)\left[\mu\left(1-n^{H}-n^{L}\right)+n^{H}\right]\right\} .
$$

The remaining steady-state aggregates can be inferred from $\kappa^{*}$. We arrive at the following result on comparative statics.

Proposition 4. An increase of $\lambda$ or $\mu$ leads to an increase of the long-run capital-intensity, wages, GDP, and aggregate TFP, and to a decrease of the long-run rate of return on capital.

For the proof take the derivatives of (12) and apply Proposition 1.

$$
\frac{\mathrm{d} \kappa^{*}}{\mathrm{~d} \lambda}=-\mu(a-1) \frac{A}{a} \cdot \frac{\partial n^{L}}{\partial \lambda}>0, \quad \frac{\mathrm{d} \kappa^{*}}{\mathrm{~d} \mu}=(a-1) \frac{A}{a}\left[\left(1-n^{H}-n^{L}\right)-\mu \cdot \frac{\partial n^{L}}{\partial \mu}\right]>0 .
$$

Then infer from (5) wages $w^{*}=(1-\alpha) A^{H}\left(\kappa^{*}\right)^{\alpha /(1-\alpha)}$ and from (6) capital returns $\left(R^{H}\right)^{*}=$ $\alpha A^{H} / \kappa^{*}$ and $\left(R^{L}\right)^{*}=\alpha A^{L} / \kappa^{*}$. Aggregate output (GDP) is defined as $y_{t}=n^{L} A^{L}\left(k_{t}^{L} / h_{t}^{L}\right)^{\alpha} h_{t}^{L}+$ $n^{H} A^{H}\left(k_{t}^{H} / h_{t}^{H}\right)^{\alpha} h_{t}^{H}$. Using (5) this simplifies to $y=\left[n^{L} h_{t}^{L}+n^{H} h_{t}^{H}\right] A^{H}\left(k_{t}^{H} / h_{t}^{H}\right)^{\alpha}$. At a steadystate GDP is thus obtained as a unique positive function of $\kappa^{*}, y^{*}=A^{H}\left(\kappa^{*}\right)^{\alpha /(1-\alpha)}$. Let aggregate TFP be defined as $\left(n^{H} A^{H}+n^{L} A^{L}\right) /\left(n^{H}+n^{L}\right)$. Then $\partial \mathrm{TFP} / \partial n^{L}=-n^{H}\left(A^{H}-\right.$ $\left.A^{L}\right) /\left(n^{H}+n^{L}\right)^{2}<0$. Applying proposition 1 provides the comparative statics of TFP. 
The model is closed by associating $\lambda$ and $\mu$ with the characteristics of the Small World network. It seems reasonable to assume that the probability to find high-ability entrepreneurs depends negatively on the average length of paths connecting people (trading partners) in the net, i.e. $\mu=\mu(L(p))$. The safety of returns of investors $\lambda$, on the other hand, is more plausibly associated with the clustering coefficient, i.e. the connectivity of local neighborhoods, $\lambda=\lambda(C(p))$. In simple words, as the economy becomes more integrated, it becomes more likely to find highreturn objects for one's investments because search through the net becomes easier; but it also becomes easier for entrepreneurs to cheat since there is less monitoring and control through tightly knit local neighborhoods.

Assumption 3 (Network Characteristics). $\mu=\mu(L(p))$ with $\mathrm{d} \mu / \mathrm{d} p>0$ and $\lim _{p \rightarrow 1} \mu=1$. $\lambda=\lambda(C(p))$ with $\mathrm{d} \lambda / \mathrm{d} p<0$.

Next recall from Figure 3 that the shortest path length $L(p)$ falls drastically at low $p$, that is at early stages of economic integration. On the other hand, $C(p)$ is high and almost invariant to $p$ at early stages of economic integration. For high $p$, that is at advanced stages of economic integration, $L(p)$ has settled almost at a low level and further increasing $p$ has the dominant effect of community disintegration captured by a falling clustering coefficient $C(p)$. From this characteristic of Small World network and Proposition 1-4 we obtain the following non-monotonous association of long-run economic integration and economic performance.

Proposition 5 (Modernization as Development). When economic integration $p$ is low rising $p$ has the dominating effect of falling $L(p)$, i.e. high profit investments are found more easily $\left(\mu(p)\right.$ rises). Rising $p$ then leads to a lower share of low-productivity firms $n^{L}$, a lower share of aggregate capital allocated to low-productivity firms $x$, a larger size of high-productivity firms $h^{H}$ and higher GDP $y$.

Proposition 6 (Modernization as Degeneration). At some intermediate stage of $p$ further rising $p$ has the dominating effect of falling $C(p)$, i.e. of less local monitoring and control $(\lambda(p)$ falls). Rising $p$ then leads to a higher share of low-productivity firms $n^{L}$, a higher share of aggregate capital allocated to low-productivity firms $x$, a smaller size of high-productivity firms $h^{H}$, and lower GDP $y$.

The two propositions summarize the pros and cons of modernization. The degeneration phase, however, is predicted only for economies in which deteriorating informal institutions are not 
properly replaced by functioning formal institutions. If $\lambda_{\min }=\lambda_{\max }$, there is no degeneration phase. Over time the model thus predicts that increasing economic integration leads first to a take-off from subsistence for all economies alike and subsequently to a degeneration phase in economies with weak formal institutions. For example, economies like South Korea and Bolivia are thus both predicted to take-off from subsistence but only Bolivia is predicted to suffer from late degeneration i.e. the existence of many low-productivity firms. Indeed, in 1993, the share of entrepreneurs and self-employed persons was 0.50 in Bolivia and 0.15 in South Korea, which was poorer than Bolivia in 1960 and about 4 times as rich in 1985 (Gollin, 2008).

But notwithstanding the drawback from weak formal institutions, we would not expect Bolivia, or any other country with weak formal institutions, to relapse to subsistence level. Instead we expect these countries to stagnate at an intermediate level of economic integration at which the pros and cons of modernization are counterbalancing each other. In order to develop such a notion of equilibrium, we have to extend the model by a feedback effect from investment to the formation of long-distance links, i.e. we have to establish a theory of endogenous network evolution.

\section{Network Evolution and Economic Performance}

In this and the next section we allow for feedback effects of economic development, measured by the capital stock held by high-productivity firms $k^{H}$ on economic integration, measured by $p$. The idea is that part of the capital stock alleviates communication, search, and travel through the net. More capital (more horses, ships, trains etc) leads to the establishment of more longdistance links and thus for any person to a higher probability of being connected with a partner from outside the own neighborhood. Specifically we assume that

$$
p_{t+1}=g\left(k_{t}^{H}\right), \quad g(0)=0, \quad g^{\prime}>0, \quad \lim _{k \rightarrow \infty} g(k)=1
$$

Without capital the economy is fully localized and for capital approaching infinity the economy is fully globalized in the sense that average path length as well as the clustering coefficient are approaching zero. For analytical convenience we have also assumed a "time to built" mechanism - this period's net investment has an impact on additional long-distance links next period - and that link formation depends on capital hold by high-productivity firms. This, however, is not

restrictive since aggregate capital $k_{t}=n_{t}^{L} k_{t}^{L}+n^{H} k_{t}^{H}$ is a unique function of $k_{t}^{H}$ via (2). The 
two simplifications allow a straightforward presentation of the economy as a two-dimensional system of difference equations in the $p-k^{H}$-space, given by (11) and (13).

The evolution of the economy over time and existence and stability of steady-states can be analyzed in a phase diagram. From (13) we get the isocline along which $\Delta p=p_{t+1}-p_{t}=0$ as $k^{H}=g^{-1}(p)$ with $k^{H}(0)=0, g^{-1^{\prime}}(p)>0$, and $\lim _{p \rightarrow 1} k^{H}=\infty$. The positively sloped $\Delta p=0$-isocline runs through the origin and has an asymptote where $p=1$, as displayed in Figure 4. We can also infer that the arrows of motion point towards higher $p$ above the curve and towards lower $p$ below.

From (11) we obtain the $\Delta k^{H}=0$-curve.

$$
k^{H}=\left[A\left(n^{H}\right)^{\alpha-1} f(p)\right]^{1 /(1-\alpha)}, \quad f(p) \equiv\left[\mu(p)\left(1-n^{H}-n^{L}(p)\right)+n^{H}\right]\left(1+\frac{x(p)}{a}\right)^{\alpha}
$$

where $n^{L}$ and $x$ depend on $p$ through the small-world architecture (Assumption 1 ) and the characteristics of the network (Assumption 3). The curvature of the $\Delta k^{H}=0$ isocline is uniquely determined by $f(p)$. Note that for $p \rightarrow 0$ and thus $\mu \rightarrow 0$ we have a subsistence economy in which $n^{L} \rightarrow\left(1-n^{H}\right)$ and $x \rightarrow\left(1-n^{H}\right) / n^{H}$.

In this case $f(p)$ collapses to the positive constant $n^{H}\left[1+\left(1-n^{H}\right) /\left(n^{H} a\right)\right]^{\alpha}$ and the (14) collapses to (15).

$$
k^{H}(0)=A^{\frac{1}{1-\alpha}}\left(n^{H}+\frac{1-n^{H}}{a}\right)^{\frac{\alpha}{1-\alpha}}>0 .
$$

The shape of the $\Delta k^{H}=0$ isocline can be discussed with help of the following Lemma (proven in the Appendix).

LEMMA 1.

$$
\operatorname{sgn} \frac{\mathrm{d} f(p)}{\mathrm{d} p}=\operatorname{sgn}\left[\frac{\mathrm{d} \mu}{\mathrm{d} p}\left(1-n^{H}-n^{L}\right)-\frac{\mathrm{d} n^{L}}{\mathrm{~d} p} \mu\right] .
$$

Building on previous insights, we know that for small $p$ the expression $\mathrm{d} \mu / \mathrm{d} p$ is large and positive and that $\mathrm{d} \lambda / \mathrm{d} p \approx 0$. This means that $\mathrm{d} n^{L} / \mathrm{d} p$ is large and negative because average length of the shortest path is rapidly falling and high-profit firms can be found more easily when $p$ rise. Taken together, this implies $\mathrm{d} f / \mathrm{d} p>0$ for small $p$. Likewise, if $p$ is large, $L(p)$ has (almost) settled down at its lower limit and thus $\mathrm{d} \mu / \mathrm{d} p \approx 0$. Without strong formal institution, however, $\mathrm{d} n^{L} / \mathrm{d} p>0$ because decreasing local clustering (decreasing $\lambda$ ) is the dominating effect when $p$ is large. Thus, without strong formal institutions, $\mathrm{d} f / \mathrm{d} p<0$ for large $p$. Summarizing, 
the $\Delta k^{H}=0$ isocline originates from a positive value $k^{H}(0)$ and is invertedly $\mathrm{u}$-shaped as displayed on the left hand side in Figure 4.

The fact that the $\Delta p$-isocline exhibits a pole at $p=1$ ensures that a unique steady-state exists at the intersection of the isoclines. Inspection of (14) reveals that the arrows of motion point towards lower $k^{H}$ above the $\Delta k^{H}$-isocline and towards higher $k^{H}$ below. The field of motion thus points towards the steady-state, which indicates stability. ${ }^{4}$ From these observations we conclude that the economy does not arrive at full economic integration. It converges towards an intermediate level of $p$, at which the negative effect of modernization on decreasing local norm enforcement (decreasing clustering) prevents further development. For $p$ above $p^{*}$ the denominating effect of increasing economic integration is the loss of trust and trustworthiness and the establishment of low-productivity firms, which deteriorates economic performance.

Figure 4: Phase Diagram: Evolving Network
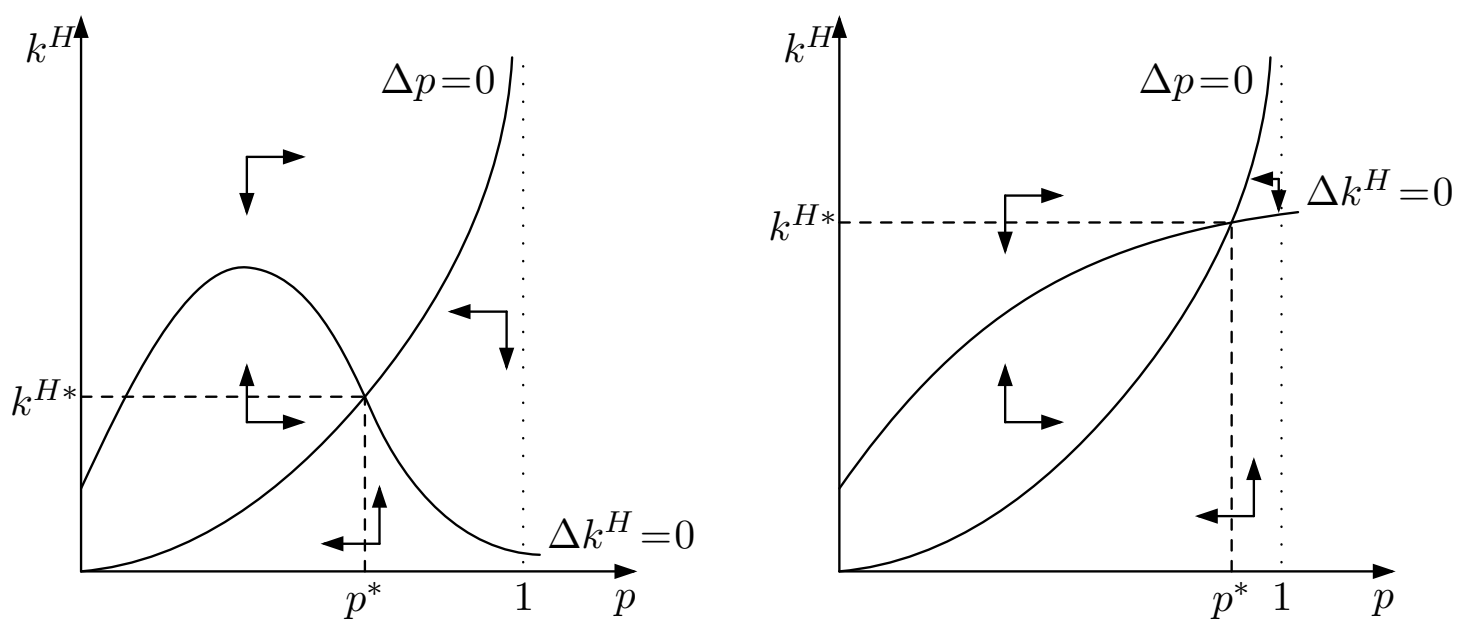

Left hand side: investor safety determined by neighborhood enforcement, $\lambda=\lambda(C(p))$. Right hand side: investor safety determined by formal institutions, $\lambda=\lambda_{\max }$.

Next consider an economy with strong formal institutions. There, $\lambda$ stays at a high value irrespective of local community structure and is thus invariant with respect to $p$. As a consequence, $\mathrm{d} n^{L} / \mathrm{d} p<0$ for all $p$. Recall from Assumption 3 that $\mu$ increases in $p$. For $p \rightarrow 1$ and thus $\mu \rightarrow 1$ we have a subsistence economy in which $n^{L} \rightarrow\left(1-n^{H}\right)$ and $x \rightarrow\left(1-n^{H}\right) / n^{H}$. For $p \rightarrow 1$, at the highest degree of globalization, investors find high-profit investments with (almost) certainty and given good formal institutions there is no drawback from deteriorating behavior

${ }^{4}$ Because the dynamics are in discrete time we cannot definitely conclude global stability from diagrammatic exposition. There might be overshooting behavior of trajectories, see Galor (2005) for a rigorous general discussion. 
of entrepreneurs and loss of community control. Diagrammatically, the downward sloping part of the $\Delta k^{H}=0$ is bent up as shown on the right hand side of Figure 4. At $p=1$, the $\Delta k^{H_{-}}$ isocline assumes a high finite value due to $f(1)=1$. Since the isocline is monotonously increasing and originating at positive $k^{H}(0)$ there exists again a unique steady-state at the intersection of the isoclines. The vector field indicates again stability. Because the $\Delta p$-isocline is invariant to the existence of formal institutions and thus the same in both Figures, we conclude that the economy with strong formal institutions arrives at a higher degree of economic integration. Applying Assumption 3 and Propositions 1-4 proves the following conclusion.

Proposition 7. Consider two otherwise identical economies. In economy 1 entrepreneurial behavior is bounded by community structure, $\lambda=\lambda(C(p)), \partial \lambda / \partial C>0$. In economy 2 entrepreneurial behavior is bounded by the rule of law, $\lambda=\lambda_{\max }$ for all $p$. Then economy 2 arrives at a higher degree of economic integration $p$ and higher stage of economic development, i.e. at a smaller number of low-productivity firms, a larger size of high-productivity firms $h^{H}$, and a higher capital labor ratio, implying higher wages, higher GDP, and higher aggregate TFP. All latter quantities increase in $\lambda$ such that economy 2 performs best at $\lambda=1$ for all $p$.

The network-based theory of modernization thus highlights the role of formal institutions for economic development as well as for social behavior, the density of the economic network, and industrial structure. In line with the evidence it predicts that in economies with weak formal institutions there co-exist many small low-productivity enterprises together with larger firms (Fafchamps, 1994, Bigsten and Soderbom, 2006). At a higher level of economic development, sustainable through strong formal institutions, the theory predicts that small low-productivity firms are largely extinct. In contrast to the earlier literature (Gollin, 2008) this difference in industrial structure across different levels of economic development is identified to be inefficient. If only formal institution were stronger, backward countries could reach a higher level of GDP and aggregate TFP .

While it seems reasonable that the economy with weak formal institutions gets stuck amidst the process of socio-economic development it is somewhat disappointing that the economy with strong formal institutions is "merely" an up-scaled version of the poorly behaving one. Intuitively we would like the economy with good institutions to grow perpetually, to develop the complete 
net of trading relationships, and to converge towards (nearly) complete elimination of lowproductivity firms. For that purpose we introduce a final important feature of networks: the spread of technological knowledge.

\section{Modernization, Knowledge Spillovers, and Long-Run Growth}

This section introduces endogenous growth through learning-by-producing in the spirit of Arrow (1962) and Romer (1986). Specifically we assume that knowledge spillovers exist such that firm-specific TFP is an increasing function of the aggregate capital stock held by highproductivity firms. Since the number of high-ability entrepreneurs is given, TFP is thus a positive function of the capital stock hold by a typical high-productivity firm, $A^{H}=\tilde{A}^{H}\left(k^{H}\right)^{\gamma}$ and $A^{L}=\tilde{A}^{L}\left(k^{H}\right)^{\gamma}$ where the $\tilde{A}$ 's subsume firm-specific productivity stemming from entrepreneurial ability.

In principle, we could allow high-productivity firms to benefit to a different (possibly higher) degree from knowledge spillovers. The present formulation however, simplifies the analysis tremendously since it keeps the productivity differential between firms constant (which is, as before, given by $a$ ). This way the differential between rates of returns on capital remains constant, a feature that allows us to go on with discussing the economy as a two-dimensional system of difference equations. In order to avoid exploding behavior we require $0 \leq \gamma \leq 1-\alpha$. As it is well known from the literature, the knife-edge case of $\gamma=1-\alpha$ generates endogenous growth (see e.g. Barro and Sala-i-Martin, 2005).

In contrast to Arrow and Romer, however, the degree of knowledge spillovers is not treated as a given constant. Due to the endogenous network structure the present model is ideally suited to rationalize a "microfoundation" of non-constant, evolving knowledge spillovers. In order to implement this idea conveniently we assume a positive and linear association of $\gamma$ with the current state of economic integration, $\gamma=\bar{\gamma} \cdot p$. The notion here is that more long-distance links lead to a greater ease at which knowledge travels through the net and thus to a higher degree to which a firm benefits from knowledge created elsewhere.

There exists corroborating evidence that the diffusion of ideas is indeed endogenous and possibly network-specific. For example, Keller (2002) and Bottazzi and Peri (2003) present evidence that knowledge spillovers are spatially localized and decay strongly with geographic distance. Keller also demonstrates that the degree of localization has shrunk substantially 
over time. Similarly, Jaffe et al. (1993) find localization effects for the links between patent creation and patent citation on the level of country, state, and metropolitan area, and that localization fades gradually over time. For DRAM production in fully developed countries Irwin and Klenow (1994) show evidence for international knowledge spillovers. At the same time, Foster and Rosenzweig (1995) present evidence that farmers in LDCs are still learning mostly from their neighbors. Andersen and Dalgaard (2011) show that across countries aggregate TFP and GDP per worker are strongly associated with the intensity of international travel.

In order to implement these insights we assume that there are no knowledge spillovers in a completely localized economy $(p=0)$. With increasing economic integration the degree of spillovers rises and $\gamma$ converges to $\bar{\gamma} \leq(1-\alpha)$ as $p$ converges to one. Taken this notion of knowledge spillovers into account equation (11) transform into (16).

$$
k_{t+1}^{H}=\left[\mu(p)\left(1-n^{H}-n^{L}(p)\right)+n^{H}\right] A\left(1+\frac{x(p)}{a}\right)^{\alpha}\left(n^{H}\right)^{\alpha-1} \cdot\left(k_{t}^{H}\right)^{\alpha} \cdot\left(k_{t}^{H}\right)^{\bar{\gamma} \cdot p} .
$$

For phase diagram analysis the $\Delta p=0$-isocline is kept from the previous section and the $\Delta k^{H}$-isocline is given by (17).

$$
k^{H}=\left[A\left(n^{H}\right)^{\alpha-1} f(p)\right]^{1 /(1-\alpha-\bar{\gamma} \cdot p)},
$$

where $f(p)$ is defined as in (14). Thus, as long as $\bar{\gamma}<(1-\alpha)$, the new $\Delta k^{H}$-isocline is just an upward bent version of the original curve. Because the $\Delta p=0$-isocline has a pole at $p=1$ and $f(p)$ continues to be finite for all $p$, there is still a unique intersection at some level of $p$. In conclusion the analysis of the previous section remains completely intact for the extension by knowledge spillovers. The qualitative behavior of the economy does not change.

Qualitative behavior changes for the knife-edge case, $\bar{\gamma}=(1-\alpha)$. Here, the fully integrated economy coincides with a Romer (1986)-economy, which displays at the aggregate level (socially) constant returns with respect to capital. Perpetual growth is possible, but in contrast to the original approach, there exist adjustment dynamics and with potentially negative repercussions from modernization, it is not a priori clear weather an economy starting at a low level of economic integration will ever reach the $A k$-growth limit.

Figure 5 shows the two possible cases. In the knife-edge case both isoclines have a pole at $p=1$. Nevertheless, an intersection of the $\Delta k^{H}=0$ and the $\Delta p=0$-isocline may prevail as shown on the left hand side in Figure 5. In that case there exists a stable poverty trap 
despite the potential of long-run growth. On the other hand, if no such intersection exists, the economy always travels towards perpetual growth and full economic integration as displayed on the right hand side of Figure 5. Apply Lemma 1 to verify that $f^{\prime}(p)>0$ for all $p$ for the case of invariant $\lambda$, in particular for strong formal institutions $\left(\lambda_{\min }=\lambda_{\max }=1\right)$. This means that there never exists a downward bending segment of the $\Delta k^{H}=0$-isocline in the case of strong formal institutions. Apply Lemma 1 for the case of weak formal institutions and investor safety determined by community control $(\lambda=\lambda(C(p)))$ to verify that the term in brackets in (17) is negatively sloped for large $p$. It is thus possible that an intersection of isoclines exist in the case of weak formal institution and neighborhood monitoring while no such intersection exists in the case of strong formal institutions.

Figure 5: Phase Diagram: Evolving Network and Knowledge Spillovers
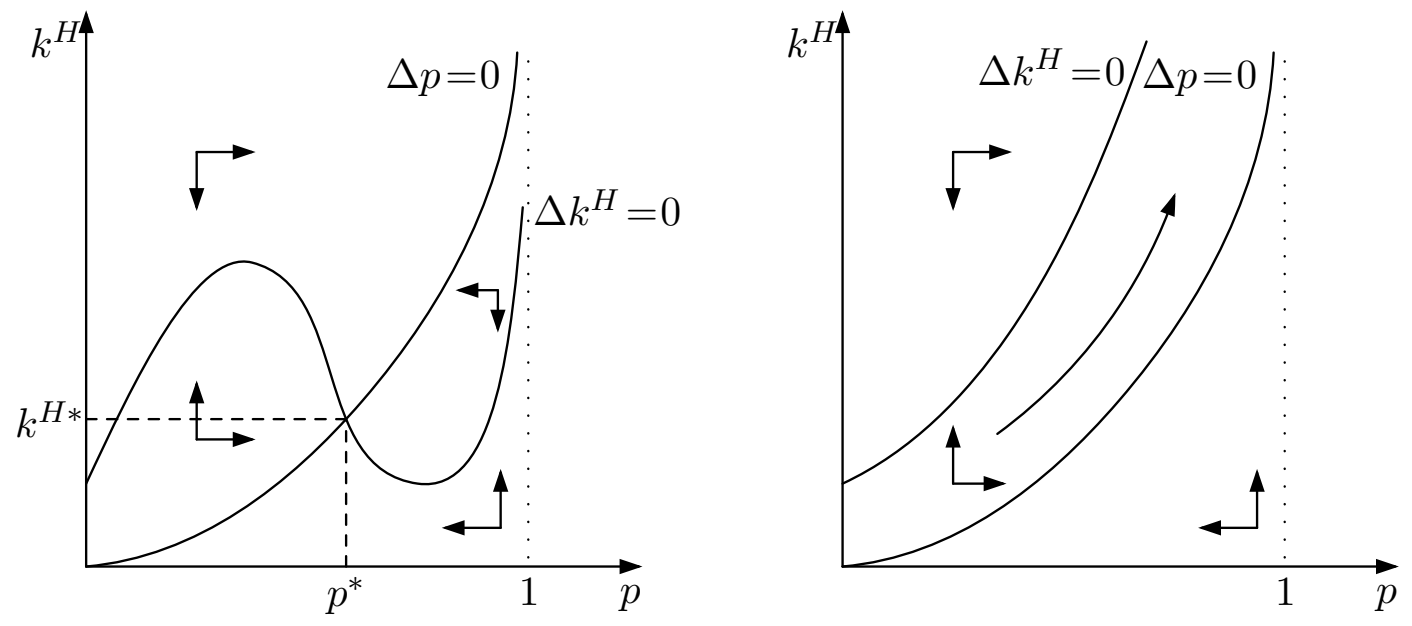

Left hand side: investor safety determined by neighborhood enforcement, $\lambda=\lambda(C(p))$. Right hand side: investor safety determined by formal institutions, $\lambda=\lambda_{\min }=\lambda_{\max }$.

Proposition 8. In the case of $\bar{\gamma}=1-\alpha$, there exists a set of parameter values $\left\{A^{H}, A^{L}, n^{H}, \alpha, \beta\right\}$ and initial values $k^{H}(0), p(0)$ for which an economy with strong formal institutions $\left(\lambda_{\text {min }}=\right.$ $\left.\lambda_{\max }\right)$ grows forever whereas an economy based on weak formal institutions and neighborhood enforcement $(\lambda=\lambda(C(p)))$ converges towards stagnation.

We prove this claim by way of example. For that purpose we consider a numerically specified version of the model.We set the capital share $\alpha$ to 0.4 and $\beta$ to 0.35 implying a savings rate of 0.25 . We set $\bar{\gamma}=1-\alpha$ in order to generate perpetual growth and $A^{H}=2.1$ so that the 
economy converges towards an annual growth rate of 2 percent in the case of strong institutions (for invariant $\lambda$ ). We set $a=2$, i.e. we assume that the return on capital is twice as high for investment in high-productivity firms as for investment in low-productivity firms, see equation (2). This implies $A^{L}=1.6$, i.e. total factor productivity in low-productivity firms is about 35 percent lower than for high-productivity firms. Furthermore we assume that high-ability entrepreneurs account for a population share of $n^{H}=0.05$.

We take the basic network parameters from the example of Figure 3. Since $m=10$ this means that everybody is assumed to have 20 neighbors. Since we have little a priori information on how to determine the parameters governing the interaction of network and economy we impose the simplest conceivable functional forms and adjust parameters such that the simulation produces plausible trajectories for economic growth from 1820-2000. We impose a simple linear function for the association between $L(p)$ and $\mu$ and the association between $C(p)$ and $\lambda$.

Specifically, we set $\mu_{\max }=0.95$ implying that high-productivity firms are found with almost certainty in the fully integrated economy (for $p=1$ ). According to Assumption $2, \lambda>1 / a$ and we set $\lambda_{\min }=0.52$ implying that without neighborhood enforcement investors get about half of the maximum return if entrepreneurs are not constraint by strong formal institutions. We set $\lambda_{\max }=0.98$ implying that investors get almost the same return as investors when investor protection is maximal. Finally we set $\mu_{\min }=0.05$, implying that $n^{L}=0.38$ in a completely localized economy (for $p=0$ ). Between these limits we interpolate $\lambda$ and $\mu$ as linear functions of $C$ and $L$ according to Assumption 3 .

The simplest function $g(k)$ fulfilling the assumptions made in (13) is the logistic, $g(k)=$ $1-e^{-\phi k}$. Of course, the choice of $\phi$ has a strong impact on dynamic behavior, which can already be inferred from Figure 5. The specification of $\phi$ determines the slope of the $\Delta p=0$ isocline. If we set a higher value for $\phi$ we assume a larger impact of economic development on network formation. Diagrammatically, as $\phi$ gets larger, the $\Delta p=0$-isocline intersects the $\Delta k^{h}=0$-isocline at lower $k^{H}$ and higher $p$. We set $\phi=0.5$ implying that for weak formal institutions the model predicts stagnation at an intermediate level of economic integration of $p^{*}=0.68$. For strong formal institutions the equilibrium of stagnation does not exist.

Figure 6 shows the predicted adjustment dynamics, assuming that a generation takes 20 years. Solid lines show trajectories for the case of fixed high $\lambda$ (the formal-institutions case) and dashed lines show behavior of an otherwise identical economy where $\lambda$ is determined by local clustering, 
$\lambda=\lambda(C(p))$, (the neighborhood-enforcement case). We have also normalized initial GDP to 100 and initial time to 1820. Around the year 1820 people came up with a series of innovations (e.g. the railway, the telegraph) which, embodied in capital investment, drastically improved reach and communication and can be thought as having initiated the process of industrialization and increasing economic integration (the second industrial revolution).

Originating from initially low $k(0)$ and $p(0)$, behavior of both economies is observationally equivalent during the early phase of industrialization. Although the new capital equipment is initially creating only a few long-distance links, as can be seen from the initially small increase of $p$, these links are - due to the small-world property - sufficient to let average distance $L(p)$ fall quite drastically. This in turn leads to a drastic increase in $\mu$, the probability at which investors find high profit investments. Consequently, the share of low-ability entrepreneurs in population $n^{L}$ falls quite drastically from almost 40 percent to almost zero.

Increasing economic integration in the 19th century initiates a first spurt of growth in both economies. At this stage, when $p$ is still quite low, growth is mainly driven by efficiency gains, i.e. by the fact that more people invest in high-productivity firms and capital stocks of highproductivity firms are getting larger. Compared to later stages at high $p$ when growth is mainly driven by technology spillovers, initial growth is (according with the historical evidence) modest.

Along with further rising capital accumulation and network evolution, the clustering coefficient begins to decline. This is of course only a drawback for the case of neighborhood-enforcement, in which declining control by neighbors leads to higher appropriation gains for entrepreneurs and less average return to investors, visible by declining $\lambda$. With contrast, the rule of law keeps $\lambda$ at its high initial position in the formal institutions case. The model thus reflects the empirical regularity found by Ahlerup et al. (2007). While neighborhood-enforcement (there interpersonal trust) has a significant impact on economic performance when strong formal institutions are absent, it is of negligible consequence otherwise. The formal-institutions economy is capable to grow by about factor 16 between 1820 and 2000, which is about the estimate of growth of income per capita in Western Europe during this period (Maddison, 2003).

While the decline of $\lambda$ sets in already around 1860 there is little discernable difference in macroeconomic behavior of both economies until the 1940's. At that time we observe what has been called the great divergence (Pomeranz, 2000, Galor, 2005). Growth of the formalinstitutions economy now really takes off, benefitting increasingly from further rising economic 
Figure 6: Adjustment Dynamics: Modernization and Growth
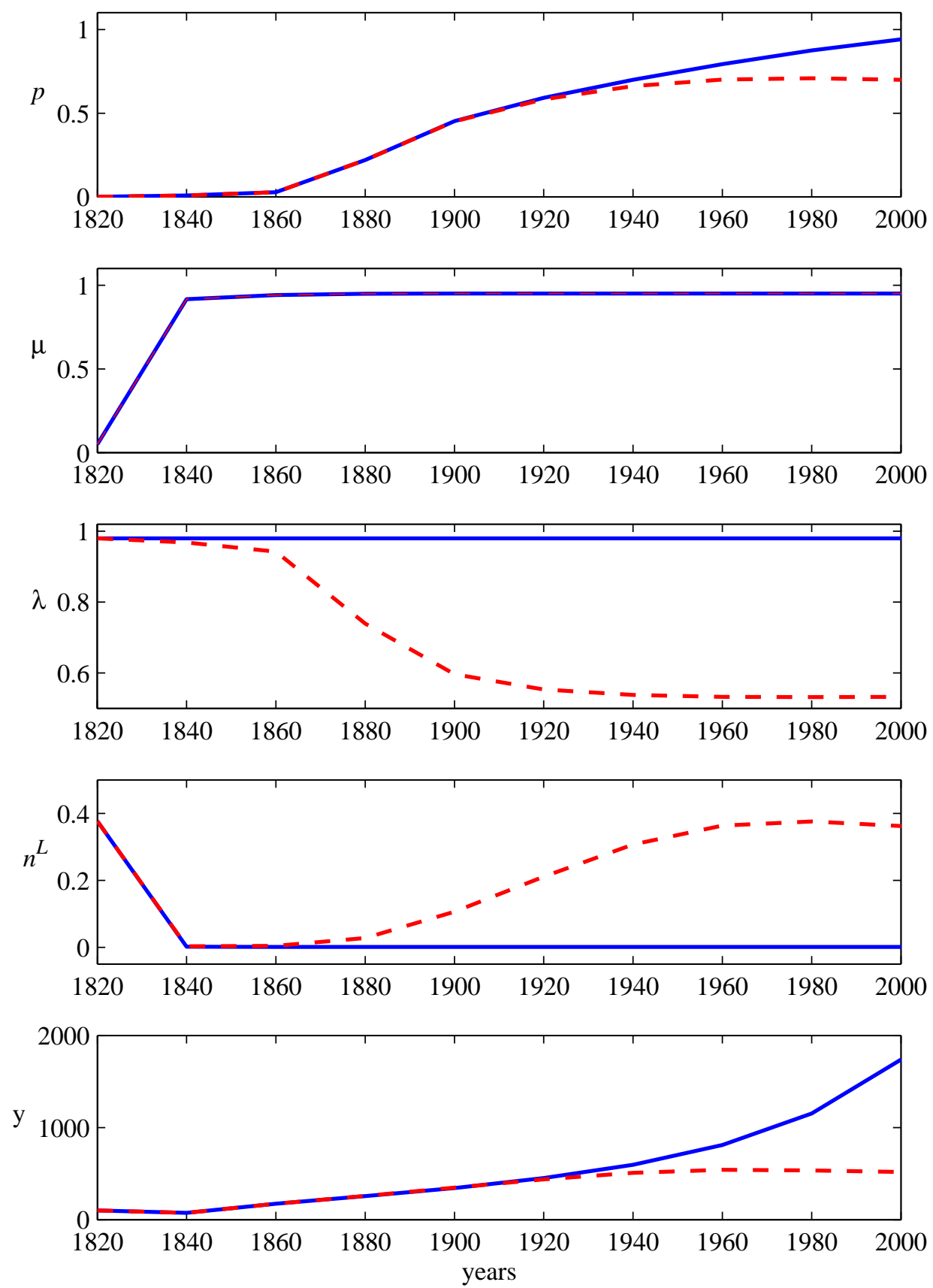

Small world network as specified for Figure 3. Parameters: $a=2, A^{H}=2.1, \alpha=0.4$, $\beta=0.35, \bar{\gamma}=0.6, n^{H}=0.05, \mu_{\min }=0.025, \mu_{\max }=0.95, \lambda_{\max }=0.98, \phi=0.5$. Solid lines: strong formal institutions, $\lambda=\lambda_{\max }$ for all $p$. Dashed lines: neighborhood enforcement, $\lambda_{\min }=0.52$.

integration and increasing knowledge spillovers. Growth in the neighborhood-enforcement economy, in contrast, phases out in the second half of the 20th century. Given less community 
monitoring, investment in firms becomes less attractive and an increasing share of people starts their own business despite their low entrepreneurial skills.

Although both countries are much more economically integrated in 20th century than in the 18th century, the neighborhood-enforcement economy fails to fully reap the fruits of economic integration. Inferior social performance causes the economy to converge towards an equilibrium where about 30 percent of the population prefers to be low-ability entrepreneur instead of investor. Industrial structure is dominated by many small firms of low-productivity. Since knowledge spillovers are created through links with high-productivity firms led by high-ability entrepreneurs, the community-enforcement economy cuts itself off from potential growth. Potentially, there are enough links to find high-profit investments with almost certainty as indicated by the $\mu$-trajectory, which is almost identical for both economies. Investors in the neighborhoodenforcement economy, however, shy away from using these links because they are not protected by strong formal institutions. With small capital stocks allocated to high-productivity firms, learning-by-doing opportunities are small and the economy does not much benefit from knowledge spillovers. Most importantly, investment in high-productivity firms is so low that the economy is not capable of long-run growth. It behaves qualitatively different from the otherwise identical formal-institutions economy that grows perpetually.

\section{Conclusion}

This paper has proposed a network-based theory of economic development. A feedback effect from economic development to network formation has allowed to discuss in a dynamic general equilibrium framework the pro and cons of modernization, understood as evolving economic and social integration. When economic integration is low and local connectivity is high, informal norms control entrepreneurial behavior and more integration mainly improves search for efficient investment opportunities. At a higher level of economic integration neighborhood enforcement deteriorates and formal institutions are needed to keep entrepreneurs in check. A gradual takeoff to perpetual growth has been explained by a feedback effect from investment to the formation of long-distance links and the diffusion of knowledge. If formal institutions are weak, however, the economy does not take off but stagnates at an intermediate income level. In line with the available evidence the model predicts that economies with weak formal institutions end up in a situation where aggregate TFP is relatively low because there exist many small low-productivity 
firms. With contrast to the earlier the presence of many small-scale, low-productivity firms has been identified as suboptimal. If only deteriorating informal norms could be replaced by strong form norms (rule of law), low productivity-firms would become eventually extinct, full economic integration would be established, and - if knowledge spillovers are sufficiently strong - the economy would grow perpetually.

Several extensions of the proposed theory are conceivable. For example, while it seems to be justifiable to treat formal institutions as predetermined (Acemoglu et al., 2001; La Porta et al., 2008), they are certainly not constant in the very long-run. Another possible extension of the model is to allow entrepreneurs to bequeath their firm to their offspring. In this context, transactions costs as another cause for inefficiently many low-productivity firms could emerge (Grossmann and Strulik, 2010). These costs could include the loss of network relations and trustworthiness if firms are not continued by family members (Caselli and Gennaioli, 2006). In a multi-country setting it seems reasonable to assume that some knowledge spills over from leadingedge countries with superior institutions to backward countries with inferior institutions (Strulik, 2010). It then seem likely that the backward country experiences slow growth rather than stagnation. Finally, other forms of network evolution are conceivable. For example, if network evolution rewires edges such that there are stars (leadership) established, it is no longer inevitable that decreasing average path length is ultimately followed by deteriorating local clustering. This effect could lead to a more optimistic view on the role of informal norms in modern societies. Integrating these ideas into the network-based theory of modernization is a potentially interesting task for future research. 


\section{Appendix}

Proof of Lemma 1. From (14):

$\frac{\mathrm{d} f(p)}{\mathrm{d} p}=\frac{\alpha}{a}\left(1+\frac{x}{a}\right)^{\alpha-1} \cdot \frac{\mathrm{d} x}{\mathrm{~d} p} \cdot\left[\mu\left(1-n^{H}-n^{L}\right)+n^{H}\right]+\left(1+\frac{x}{a}\right)^{\alpha}\left[\frac{\mathrm{d} \mu}{\mathrm{d} p}\left(1-n^{H}-n^{L}\right)-\mu \frac{\mathrm{d} n^{L}}{\mathrm{~d} p}\right]$.

Inserting

$\frac{\mathrm{d} x}{\mathrm{~d} p}=\frac{\mathrm{d} x}{\mathrm{~d} n^{L}} \frac{\mathrm{d} n^{L}}{\mathrm{~d} p}+\frac{\mathrm{d} x}{\mathrm{~d} \mu} \frac{\mathrm{d} \mu}{\mathrm{d} p}, \quad \frac{\mathrm{d} x}{\mathrm{~d} n^{L}}=\frac{\mu}{\left[\mu\left(1-n^{H}-n^{L}\right)+n^{H}\right]^{2}}, \quad \frac{\mathrm{d} x}{\mathrm{~d} p}=-\frac{1-n^{H}-n^{L}}{\left[\mu\left(1-n^{H}-n^{L}\right)+n^{H}\right]^{2}}$

the derivative simplifies to

$$
\frac{\mathrm{d} f(p)}{\mathrm{d} p}=\frac{1}{a}\left(1+\frac{x}{a}\right)^{\alpha-1}\left[\frac{\mathrm{d} \mu}{\mathrm{d} p}\left(1-n^{H}-n^{L}\right)-\frac{\mathrm{d} n^{L}}{\mathrm{~d} p} \mu\right] \cdot\left\{a+x-\frac{\alpha}{\mu\left(1-n^{H}-n^{L}\right)+n^{H}}\right\} .
$$

Since $a>1$, a sufficient condition for the term in curly parenthesis to be positive is

$$
1+x-\frac{\alpha}{\mu\left(1-n^{H}-n^{L}\right)+n^{H}}>0 .
$$

After inserting $x$ from (2) the condition simplifies to

$$
\frac{1-\alpha}{\mu\left(1-n^{H}-N^{L}\right)+n^{H}}>0
$$

which is true. The sign of $\mathrm{d} f(p) / \mathrm{d} p$ is thus determined by the sign of the term in square brackets, which gives Lemma 1. 


\section{REFERENCES}

Acemoglu, D., S. Johnson, J.A. Robinson, 2001, The colonial origins of comparative development: An empirical investigation, American Economic Review 91, 1369-1401.

Ahlerup, P., Olsson, O., and D. Yanagizawa, 2007, Social capital vs. institutions in the growth process, European Journal of Political Economy 25, 1-14.

Andersen, T.B. and Dalgaard, C.-J., 2011, Flows of People, Flows of Ideas, and the Inequality of Nations, Journal of Economic Growth 16, 1-32.

Annen, K., 2003, Social capital, inclusive networks, and economic performance, Journal of Economic Behavior $\& 3$ Organization 50, 449-463.

Arrow, K.J., 1962, The economic implications of learning-by-doing, Review of Economic Studies $29,155-173$.

Bigsten, A. and Soderbom, M., 2006, What have we learned from a decade of manufacturing enterprise surveys in Africa?, The World Bank Research Observer 21, 241-265.

Bottazi, L. and G. Peri, 2003, Innovation, demand, and knowledge spillovers: Evidence form European patent data, European Economic Review 47, 687-710.

Caselli, F. and Gennaioli, N., 2006, Dynastic management, Discussion Paper, LSE.

Djankov, S., La Porta, R., Lopez-de-Silanes, F. and Shleifer, A. 2003, Courts, Quarterly Journal of Economics 118, 453-517.

Durlauf, S. and M. Fafchamps, 2005, Social capital, in: P. Aghion and S. Durlauf, Handbook of Economic Growth Vol 1A, Amsterdam, North-Holland.

Fafchamps, M., 1994. Industrial structure and microenterprises in Africa, Journal of Developing Areas 29, 1-30.

Fafchamps, M., 2001, Networks, communities, and markets in Sub-Saharan Africa: implications for firm growth and investment, Journal of African Economics 10, AERC Supplement 2, $1009-142$.

Farmer, A. and R. Kali, 2007, Economic progress, social regress?, Journal of Public Economic Theory 9, 501-520.

Fogli, A. and L. Veldkamp, 2011, Germs, social networks and growth, mimeo, University of Minnesota.

Foster, A.D. and Rosenzweig, M.R., 1995, Learning by doing and learning from others: Human capital and technical change in agriculture, Journal of Political Economy 103, 1176-1209.

Francois, P. and J. Zabojnik, 2005, Trust, social capital, and economic development, Journal of the European Economic Association 3, 51-94.

Fukuyama, F., 1995, Trust: The Social Virtues and the Creation of Prosperity, Free Press, New York. 
Galor, O., 2005, From stagnation to growth: unified growth theory, in: P. Aghion and S. Durlauf, Handbook of Economic Growth Vol 1A, Amsterdam, North-Holland.

Galor, O., 2005, Discrete Dynamical Systems, book manuscript, Brown University.

Gollin, D., 2008, Nobody's business but my own: Self-employment and small enterprise in economic development, Journal of Monetary Economics 55, 219-233.

Granovetter, M.S., 1973, The strength of weak ties, American Journal of Sociology 78, 13601380.

Grossmann, V. and H. Strulik, 2010, Should continued family firms face lower taxes than other estates? Journal of Public Economics 94, 81-101.

Guiso, L., L. Zingales, and P. Sapienza, 2008, Social capital as good culture, Journal of the European Economic Association 6, 295-320.

Humphrey, J. and H. Schmitz, 1998, Trust and inter-firm relations in developing and transition economies, Journal of Development Studies 34, 32-61.

Inglehart, R. and W.E. Baker, 2000, Modernization, cultural change, and the persistence of traditional values, American Sociological Review 65, 19-51.

Irwin, D.A. and Klenow, P.J., 1994, Learning-by-doing spillovers in the semiconductor industry, Journal of Political Economy 102, 1200-1227.

Jaffe, A. M. Tratjenberg, and R. Henderson, 1993, Geographic localization of knowledge spillovers as evidenced by patent citations Quarterly Journal of Economics 63, 577-598.

Karlan, D., Mobius, M.,Rosenblat, T. and Szeidl, A., 2009, Trust and Social Collateral, Quarterly Journal of Economics 124, 1307-1361.

Keller, W., 2002, Geographic localization of international technology diffusion, American Economic Review 92, 120-142.

Knack, S. and P. Keefer, 1997, Does social capital have an economic payoff? A cross country investigation, Quarterly Journal of Economics 112, 1251-1288.

Kremer, M., 1993, The O-ring theory of economic development, Quarterly Journal of Economics 108, 551-575.,

Kumar, K.B. and J.G. Matsusaka, 2009, From families to formal contracts: an approach to development, Journal of Development Economics 90, 106-119.

Kuznets, S., 1966, Modern Economic Growth: Rate, Structure and Spread, Yale University Press, New Haven.

La Porta, R., Lopez-de-Silanes, F., Shleifer, A., Vishny, R.W, 1997. Trust in large organizations, American Economic Review 87(2), 333-338.

La Porta, R., Lopez-de-Silanes, F., Shleifer, A., The economic consequences of legal origins, Journal of Economic Literature 46, 285-332. 
Lucas, R.E., 1978, On the size distribution of business firms, Bell Journal of Economics 9, 508-523.

Milgram, S., 1967, The small world problem, Psychology Today 2, 60-67.

Newman, M.E.J., C. Moore, and D.J. Watts, 2000, Mean-field solution of the small world network model, Physics Review Letters 84, 3201-3204.

Newman, M.E.J., 2003, The structure and function of complex networks, SIAM Review 45, 167-256.

Polanyi, K., 1957, The Great Transformation: The Political and Economic Origins of Our Time, Beacon, Boston.

Pomeranz, K., 2000, The Great Divergence: China, Europe, and the Making of the Modern World, Princeton, Princeton University Press.

Putnam, R.D., R. Leonardi, and R.Y. Nanetti, 1993, Making Democracy Work: Civic Traditions in Modern Italy, Princeton University Press, Princeton.

Romer, P.M., 1986, Increasing returns and long-run growth, Journal of Political Economy 94, 1002-1037.

Routledge, B.R. and Von Amsberg, J., 2003, Social capital and growth, Journal of Monetary Economics, 50, 167-193.

Rostow, W.W., 1959, The stages of economic growth, Economic History Review 12, 1-16.

Strulik, H., 2010, Knowledge and Growth in the Very Long-Run, University of Hannover, Discussion Paper 459.

Tabellini, G., 2008, The scope of cooperation: values and incentives, Quarterly Journal of Economics 123, 905-950.

Tabellini, G., 2010, Culture and institutions: economic development in the regions of Europe, Journal of the European Economic Association 8, 677-716.

Watts, D.J., and S.H. Strogatz, 1998, Collective dynamics of "small-world" networks, Nature 393, 440-442.

Zak, P.J. and S. Knack, 2001, Trust and growth, Economic Journal 111, 295-321. 